\title{
Contrastive Study on Torque Distribution of Distributed Drive Electric Vehicle under Different Control Methods
}

\author{
Xiao-gang $\mathrm{Wu}^{1,2}$ and Dian-yu Zheng ${ }^{1}$ \\ ${ }^{1}$ Electrical and Electronic Engineering College, Harbin University of Science and Technology, Harbin 150080, China \\ ${ }^{2}$ Key Laboratory of Advanced Manufacture Technology for Automobile Parts, Chongqing University of Technology, \\ Ministry of Education, Chongqing 400054, China \\ Correspondence should be addressed to Xiao-gang Wu; xgwu@hrbust.edu.cn
}

Received 1 June 2017; Accepted 16 July 2017; Published 17 August 2017

Academic Editor: Benoit Iung

Copyright (C) 2017 Xiao-gang Wu and Dian-yu Zheng. This is an open access article distributed under the Creative Commons Attribution License, which permits unrestricted use, distribution, and reproduction in any medium, provided the original work is properly cited.

\begin{abstract}
This paper uses certain hub motor distributed electric vehicle driving system as the research object, using several control strategies, such as dynamic programming global optimization algorithm, fuzzy control, and torque equal distribution and realizing the distribution control of the distributed power of the electric drive system. The simulation results show that, under the NEDC road condition, using the dynamic programming algorithm to optimize the torque distribution, the energy consumption of the electric drive system is $8041 \mathrm{~kJ}$, decreased by $4.77 \%$ compared to the average torque distribution control and decreased by $3.5 \%$ compared to the fuzzy control strategy. The power consumption of the electric vehicle is $20.25 \mathrm{kWh}$ per $100 \mathrm{~km}$, decreased by $1.01 \mathrm{kWh}$ compared to the average torque distribution control strategy and decreased by $0.72 \mathrm{kWh}$ compared to the fuzzy control strategy. Under the fixed working condition, the energy efficiency of power system can be improved effectively when the distributed dynamic system torque is optimized by the dynamic programming algorithm. Without considering the global optimization, the fuzzy control can effectively improve the energy efficiency of the power system compared to the torque average distribution strategy.
\end{abstract}

\section{Introduction}

Compared to traditional single motor drive mode, the power system of the electric vehicle driven by distributed hub motor eliminates some transmission device and has the advantages of high transmission efficiency and compact structure [1].

On torque distribution research of distributed drive electric vehicle, Shen et al. [2], through the analysis of modeling of simulation for the four-wheel drive motor and inverter device, put forward the torque between the front and rear wheels of a fixed ratio distribution which can improve the vehicle energy efficiency. Zou [3] have established the comprehensive optimization function to the four-wheel vehicle mobility and the stability. Zhang [4] based on the fact that the motor loss model of input and output characteristics of electric drive system is derived, using convex optimization to optimize the analysis results of different spatial distribution optimization of torque motor configuration, proposed accelerating coasting mode. Yamakawa and Watanabe [5] studied the driving force distribution strategy of the four-wheel drive system of automobile and established the evaluation of quadratic function according to the longitudinal and lateral adhesion of each drive wheel and minimized the longitudinal adhesion and lateral adhesion of each drive wheel, to achieve the distribution of driving force. Yu et al. [6], through the establishment of vehicle model, using mathematical analysis method to calculate the front and rear wheel torque distribution coefficient, according to torque coefficient distribution motor torque, can improve the motor utilization efficiency. Zhu et al. [7] on the wheel hub motor and ISG motor model of 4WD HEV configuration were studied by fuzzy logic control and ISG electric motor to control the battery SOC balance and improve the overall efficiency of energy conversion. Gu et al. [8], based on experimental data, establishing mathematical model of the key components of electric vehicles, in order to reduce the energy consumption of the system as the goal, put forward a kind of drive torque distribution efficiency optimization control strategy of transmission system based 
on torque distribution method and, compared to a fixed proportion, can reduce the power consumption of about $5 \%$. Wang et al. [9] suggest that when the torque demand is small, using only two-wheel driving vehicle gives better efficiency. In Lu et al. [10], based on the efficiency model of permanent magnet brushless wheel motor, the efficiency model of multipermanent magnet synchronous motor with the same torque and speed is established. The simulation results show that the four-wheel hub motor electric vehicle is better than time-sharing two-wheel drive and full-time two-wheel drive. In summary, the domestic and foreign study of distributed driving torque strategy are mainly based on motor loss model and wheel adhesion optimization model. The control method of the motor torque distribution based on the intuitionistic logic threshold allocation strategy and numerical interpolation method has lower calculation precision and its potential is small. Although the local optimal solution can be obtained using local optimization algorithm control strategy, the local optimization requires specific conditions and cannot achieve the optimal energy efficiency of electric vehicle electric drive system within the whole cycle conditions.

Aiming at a hub motor distributed drive system and considering the characteristics of the hub motor efficiency distribution, the torque distributed of the hub motor is assigned by the dynamic programming global optimization algorithm, the fuzzy control, and the torque average distribution control method, respectively. Through the energy efficiency comparison of the electric drive system, the control method of the optimal torque distribution of the distributed driving power system under different conditions is obtained.

\section{Working Principle of Distributed Drive Power System}

The power system structure of the distributed drive electric vehicle is shown in Figure 1. The main structure includes a hub motor, a vehicle controller, a motor controller, and a power battery. The mutual transformation of electrical energy and mechanical energy for the power battery is realized by the motor controller and the hub motor, and the hub motor is connected with the wheel and drives the vehicle directly.

Distributed drive electric vehicles and centralized single motor drive system compared to the distributed drive electric vehicle motor controller can control the flexible control of the four-wheel driving motor output torque, so that the motor is running in the best working area, improve work efficiency, and reduce the energy consumption of driving. The basic operation modes of distributed drive include full-time twowheel drive, full-time four-wheel drive, and time shared twowheel or four-wheel drive mode.

In the full-time two-wheel drive mode, the vehicle running energy is supplied by a power battery, and the vehicle controller sends a control signal to drive the front wheel motor to drive the electric vehicle. The run mode is shown in Figure 2.

In the full four-wheel drive mode, the energy of the whole vehicle is supplied by a power battery, and the controller of the whole vehicle sends out a control signal to drive the front/rear motor to run together and drive the electric vehicle. The run mode is shown in Figure 3.

Time-sharing two-wheel and four-wheel switching mode is when the electric vehicle's demand power is less than a certain threshold, the vehicle controller issued a control signal, the use of two-wheel drive, the power battery to the front wheel motor drive energy, as shown in Figure 2. When the electric car's demand power is greater than the threshold, the use of four-wheel drive, powered by the battery to the four-drive motor to provide energy, not only meets the dynamic requirements, but also can improve the motor efficiency, as shown in Figure 3. Therefore, the main control method of distributed driving electric vehicle is considered under different conditions according to the change of power demand to decide the two-wheel drive or four-wheel drive mode control of drive mode, and the main goal is to improve the working efficiency of the drive motor [11].

\section{Modeling of Distributed Drive Power Systems}

3.1. Dynamics Model. According to the torque transmission of the power system of the distributed electric vehicle, the dynamic system satisfies the dynamic system equilibrium equation at the $t$ moment and is obtained by

$$
P_{\mathrm{dem}}(t)=P_{m}(t)+P_{\mathrm{loss}, m}(t)
$$

where $P_{m}$ is the output of the motor cycle by operation of the driving power and $P_{\text {loss }, m}$ is the motor converted from electrical power into mechanical power in static power loss; because the power system demand power $P_{\text {dem }}$ is provided by the battery, so formula (1) can be described as

$$
P_{m}(t)+P_{\text {loss }, m}(t)=P_{b}(t),
$$

where $P_{b}$ is battery power.

Under cyclic conditions, the demand driving power of the whole vehicle can be calculated by

$$
\begin{aligned}
& P_{\mathrm{dem}}(t)=F_{\mathrm{dem}}(t) v(t), \\
& F_{\mathrm{dem}}(t)=m \cdot \frac{d v(t)}{d t}+F_{a}(t)+F_{f}(t)+F_{g}(t),
\end{aligned}
$$

where $m$ is the total mass of electric vehicles; $F_{\mathrm{dem}}$ is the driving force of the power system operation cycle; $F_{a}$ is air resistance; $F_{f}$ is rolling friction; $F_{g}$ is slope resistance, as the specific expression of types (4), (5), and (6) is shown:

$$
\begin{aligned}
& F_{a}(t)=\frac{1}{2} \cdot \rho_{a} \cdot c_{d} \cdot A \cdot v^{2}(t), \\
& F_{f}(t)=m \cdot g \cdot c_{r} \cdot \cos (\alpha(t)), \\
& F_{g}(t)=m \cdot g \cdot \sin (\alpha(t)),
\end{aligned}
$$

where $\rho_{a}$ refers to the air density; $c_{d}$ is the air resistance coefficient; $A$ is the windward area; $c_{r}$ is rolling resistance coefficient; $\alpha(t)$ is the $t$ moment of road slope. 


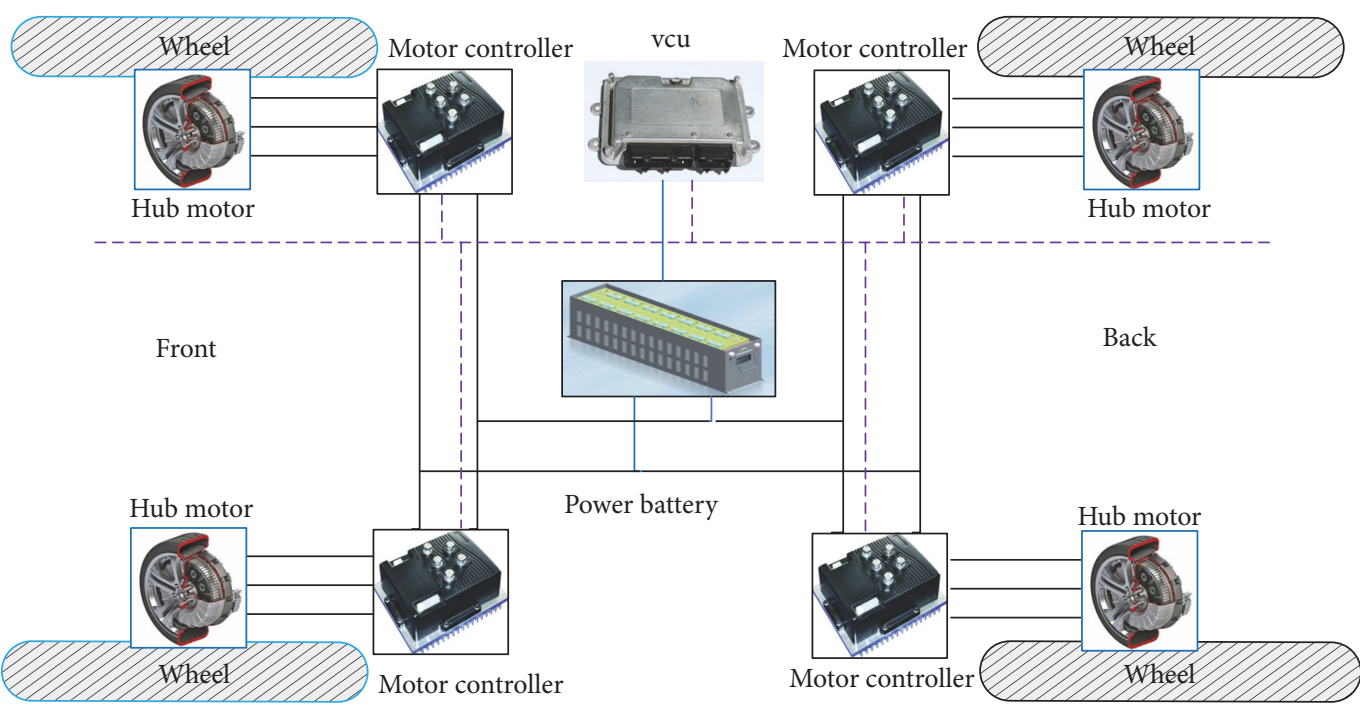

FIGURE 1: System diagram of a distributed drive electric vehicle.

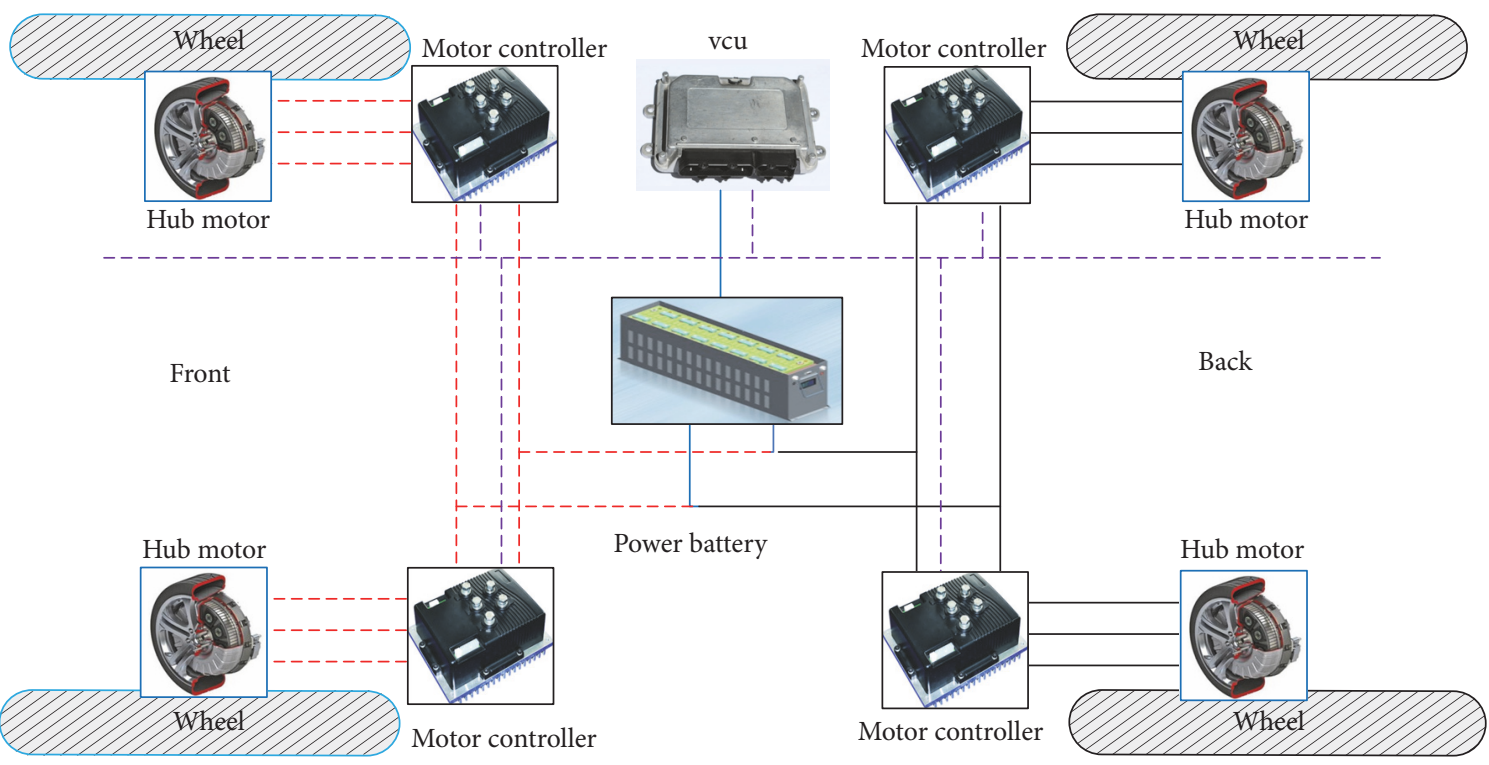

FIGURE 2: Two-wheel drive mode.

3.2. Motor Model. In order to reduce the computational burden of the system, the hub motor model ignores the dynamic characteristics of the motor, and the conversion of electrical power into mechanical power existed in the process of conversion efficiency, so static MAP is used which forms as a model of drive motor [12], as shown in Figure 4. At the same time, drive motors need to meet conditions such as

$$
\begin{aligned}
& P_{m}(t)=T_{m}(t) \omega_{m}(t), \\
& T_{m}(t) \in\left[T_{m, \min }\left(\omega_{m}(t)\right), T_{m, \text { max }}\left(\omega_{m}(t)\right)\right], \\
& \omega_{m}(t) \in\left[0, \omega_{m, \text { max }}(t)\right],
\end{aligned}
$$

where $T_{m}$ and $\omega_{m}$ are the drive motor output torque and speed, respectively.

\section{Torque Distribution Strategy}

Due to the increase of driving components, the control strategy of distributed drive car is more complex than that of the traditional car. Because of the complexity and nonlinearity of its controlled objects, it is necessary to find a control method with strong robustness and non-linear optimization. Compared with the traditional control strategy, this paper improves the drive motor efficiency through the optimal allocation of driving torque and makes the drive motor work in a high speed zone at a certain speed.

In this paper, the optimal torque distribution control can be expressed as the determination of the torque distribution factor $k$ of front and rear wheels (shafts). The coefficient $k$ is defined as the torque distribution characteristic between 


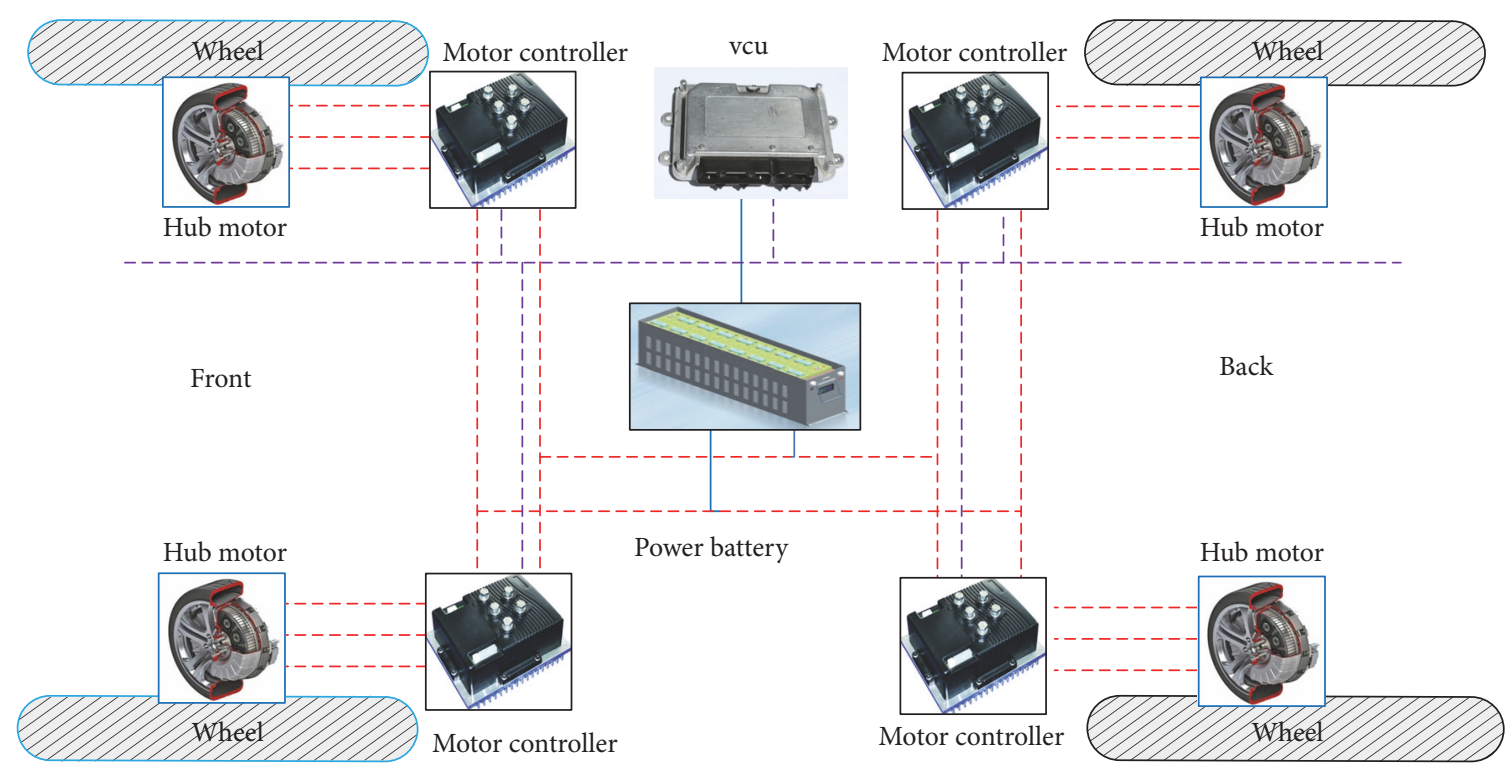

FIGURE 3: Four-wheel drive mode.

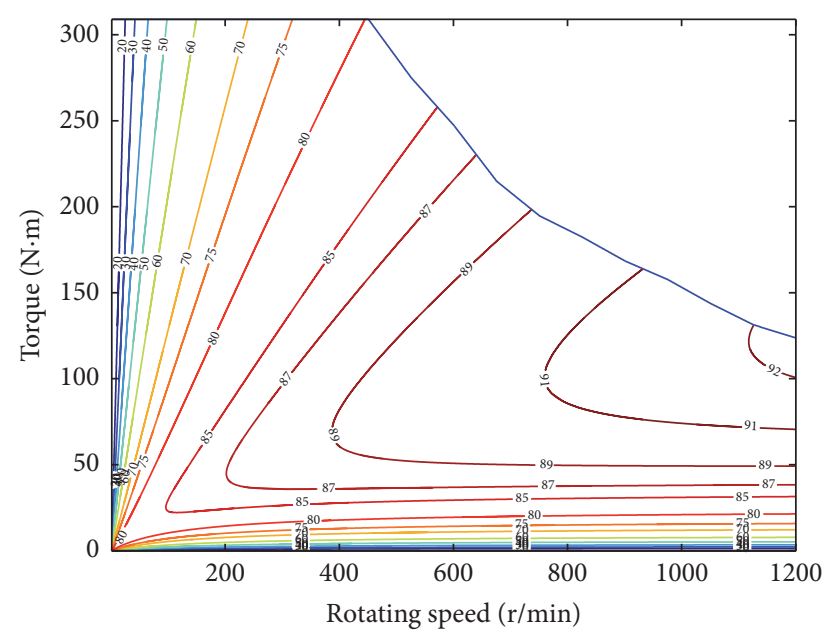

Efficiency area distribution

_ Maximum external characteristic curve

Figure 4: Drive motor efficiency MAP diagram.

the front and rear wheels (shafts) after the start of control, as shown in (8), and the boundary conditions are defined as formulas (9)-(12):

$$
\begin{aligned}
k & =\frac{T_{f}}{\left(T_{f}+T_{r}\right)}, \\
T_{f}+T_{r} & =T_{\text {req }}, \\
0 & \leq T_{f} \leq \frac{T_{\text {req }}}{2}, \\
0 & \leq T_{r} \leq \frac{T_{\text {req }}}{2}, \\
0 & \leq k \leq 1 .
\end{aligned}
$$

In the model, $T_{f}$ is the front wheel torque value, $T_{r}$ is the rear wheel torque value, and $T_{\text {req }}$ is the automobile torque demand.

When $k=0$, the individual rear wheel drive is indicated. When $k=1$, the individual front wheel drive is indicated. When $k=0.5$ is expressed as the four-wheel torque average distribution mode, taking into account the same single rear wheel drive and front wheel drive effect alone, here can be further on the coefficient $k$ the following limits: if $0=k=0.5$ or $k=0$, it will be considered to be front or rear drive alone; if $k=0.5$, it will be considered to be the four rounds of the average distribution of torque [13].

In the case of wheel motor drive, the drive energy utilization efficiency is

$$
\begin{aligned}
\max \eta & =\left[\frac{k T_{\mathrm{dem}}}{\eta_{f}\left(k T_{\mathrm{dem}}, n\right)}+\frac{(1-k) T_{\mathrm{dem}}}{\eta_{r}\left((1-k) T_{\mathrm{dem}}, n\right)}\right]^{-1}, \\
n & <n_{\max }, \\
0 & <T_{f}<T_{\mathrm{dem}}, \\
0 & <T_{r}<T_{\mathrm{dem}}, \\
T_{\mathrm{dem}} & <T_{\max } .
\end{aligned}
$$

Under the disturbance of ignoring other factors, the comprehensive efficiency of the system can be obtained under the driving condition, and the energy consumption of the motor drive system under the driving condition can be simplified as follows:

$$
E=\int_{0}^{t}\left(p_{\mathrm{dem}} * \eta\right) d t
$$

4.1. Dynamic Programming Control Strategy. In the actual domain $\left[t_{0}, t_{f}\right]$, the state variables in the distributed drive 
power system optimization problem are vehicle speed and torque $T_{\text {dem }}$ [14]. Because the speed can be determined according to the operating conditions, the state variable is denoted as $x(t)=\left[T_{\mathrm{dem}}(t)\right]$, the required power of the vehicle is a control variable, denoted as $u(t)=\left[P_{\mathrm{dem}}(t)\right]$. The distributed electric vehicle power system in a discrete state can be described by the equation of state (15) [15].

$$
\dot{x}=f(x(k), u(k)),
$$

where $f$ is the dynamic system equation of electric vehicle, which consists of (1) to (6). Constraints are on state spaces, such as expressions

$$
\begin{aligned}
0 & \leq P_{\text {dem }} \leq P_{\text {dem,max }}, \\
T_{m, \text { min }} & <T_{\text {dem }}(t)<T_{m, \max },
\end{aligned}
$$

where $T_{\text {dem }}$ is the hub motor torque; $T_{m, \text { min }}$ and $T_{m, \text { max }}$, respectively, represent the motor minimum and maximum torque; $P_{\mathrm{dem}, \max }$ is the maximum output power of wheel motor.

In this paper, the electric drive system energy efficiency is taken as the objective function, and the objective function is shown in

$$
J=\max \sum_{i=0}^{N}\left[\frac{k T_{\mathrm{dem}}}{\eta_{f}\left(k T_{\mathrm{dem}}, n\right)}+\frac{(1-k) T_{\mathrm{dem}}}{\eta_{r}\left((1-k) T_{\mathrm{dem}}, n\right)}\right]^{-1},
$$

where $T_{f}$ is the front wheel torque value; $T_{r}$ is the rear wheel torque value; $\eta_{f}$ is front wheel efficiency; $\eta_{r}$ is the rear wheel efficiency.

As the dynamic programming adopts numerical method, the time and the system state are discretized, and the computational grid of the torque distribution ratio is divided along the time direction of the driving cycle. According to the known driving cycle, the vehicle model is used to calculate the power demand and power and speed of the driving cycle along the time direction. According to the motor constraints, respectively, from the initial state of the system and the termination conditions, the driving cycle of the system can reach boundary in the boundary range, to meet the system constraint condition, according to the forward calculation design target function, obtaining the torque distribution of the entire driving cycle than the state matrix. Finally, this paper uses the recursive call method to reverse the state from the termination state to the initial state, complete the traversal optimization process, obtain torque distribution trajectory, and output the calculation results. The dynamic programming method is shown in Figure 5 [16].

The dynamic programming method is used to realize the torque distribution of hub motor, as shown in Figure 6.

4.2. Fuzzy Control Strategy. Fuzzy control rules are designed according to engineering experience and are suitable for the control of complex systems such as multimotor drive [17]. The control strategy should take into account the demand torque $T_{\text {req }}$ of the vehicle, make the vehicle drive state for twowheel or four-wheel drive, and take into account the motor efficiency, so that the motor work is in the high efficiency zone.

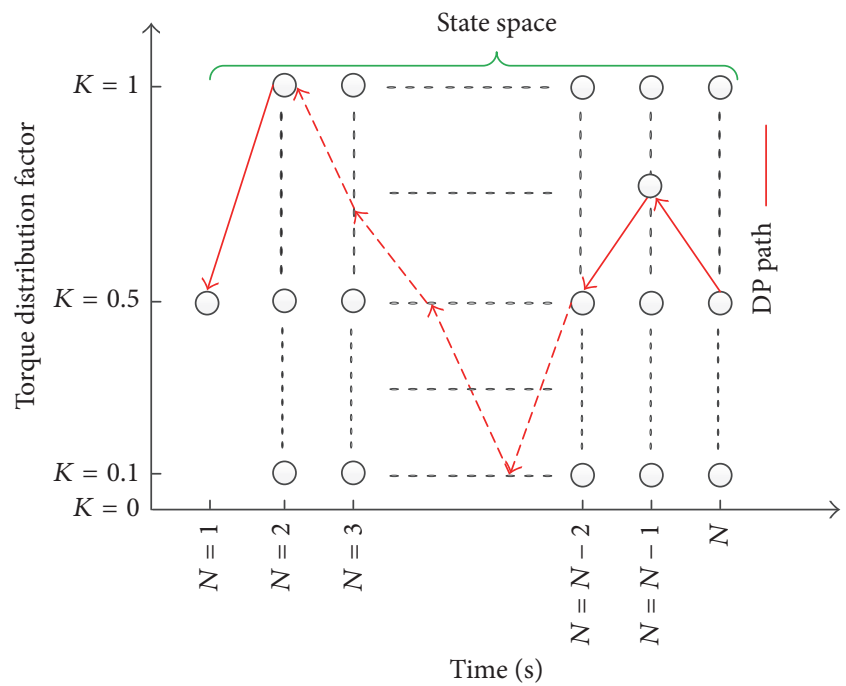

FIGURE 5: Schematic diagram of dynamic programming control method.

For the membership function of the fuzzy set, the triangle membership function is simple, and the response speed is fast [18]. Therefore, the fuzzy control input and output functions use triangle membership functions. The membership functions for input torque and speed and the output factor $k$ are shown in Figures 7, 8, and 9, respectively.

The fuzzy subsets of torque $T:\{\mathrm{NB}, \mathrm{NM}, \mathrm{NS}, \mathrm{Z}, \mathrm{PS}$, $\mathrm{PM}, \mathrm{PB}\}$;

The fuzzy subsets of speed $n$ : $\{\mathrm{NB}, \mathrm{NM}, \mathrm{NS}, \mathrm{Z}, \mathrm{PS}$, $\mathrm{PM}, \mathrm{PB}\}$;

The fuzzy subsets of assigned proportions: $\{\mathrm{NB}, \mathrm{NM}$, NS, Z, PS, PM, a, PB\}.

Among them, NB means minimal, NM means small, NS means smaller, $\mathrm{Z}$ means medium, PS means larger, PM means large, and PB means great [19].

According to the characteristics of the distributed driving system, the fuzzy control rules are designed according to the following [20], and the fuzzy control rule table is shown in Table 1:

(1) When the torque demand of front wheel drive motor is less than the total torque demand $T_{\text {req }}$, the average distribution drive mode is adopted.

(2) When the torque demand of the front wheel drive motor is greater than the total torque demand, $T_{\text {req }}$ adopts a separate two-wheel drive mode.

In this paper, the maximum membership degree method is used to calculate the defuzzification. For a discrete domain with $M$ output quantization series, the formula is shown in formula [21]

$$
v_{0}=\frac{1}{N} \sum_{i=1}^{N} \max _{v \in V}\left(\mu_{v}(v)\right) .
$$




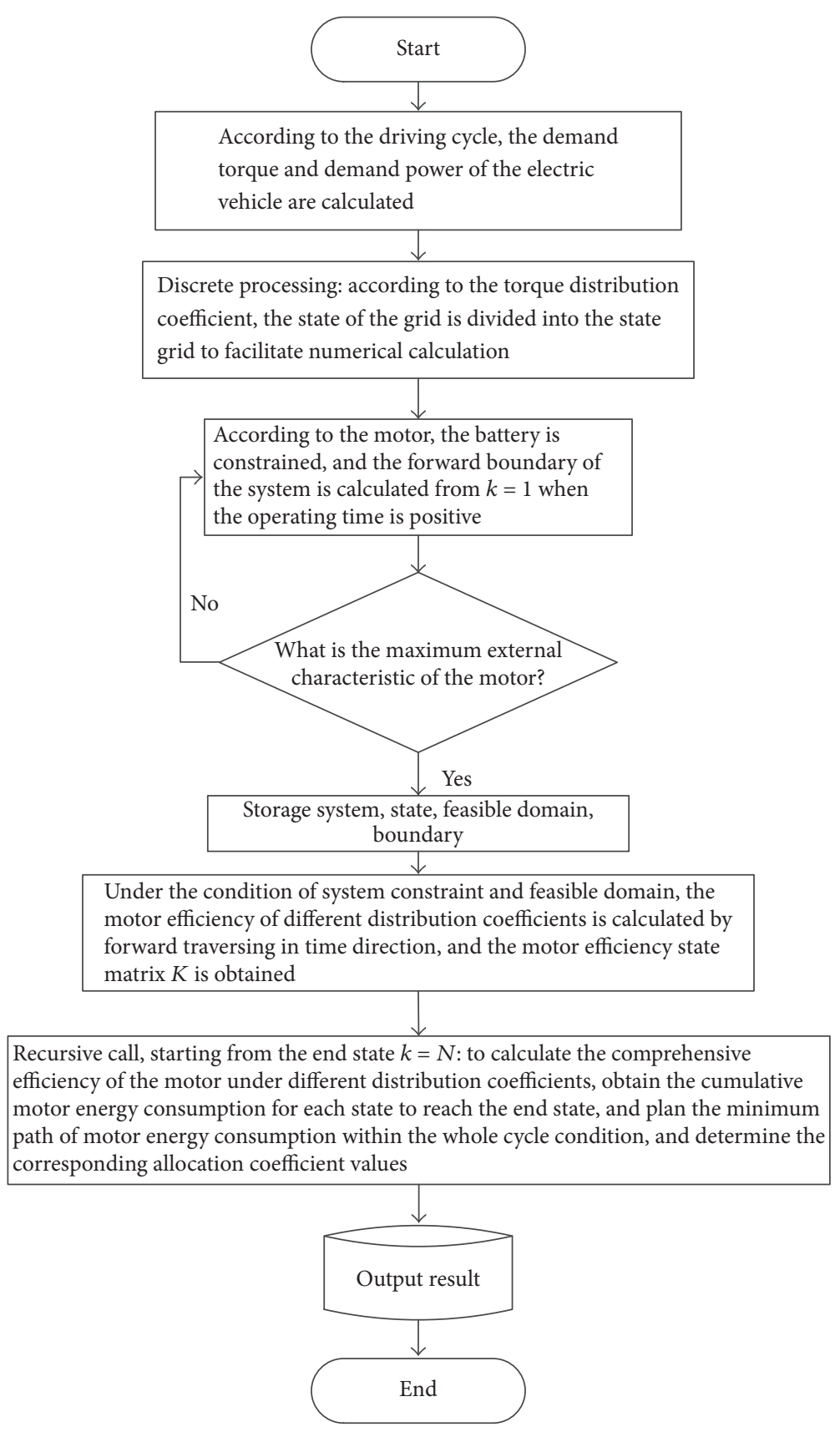

FIGURE 6: Dynamic programming method to realize the torque flow chart of hub motor.

TABLE 1: Fuzzy control rule table.

\begin{tabular}{|c|c|c|c|c|c|c|c|}
\hline \multirow{2}{*}{$n$} & \multicolumn{7}{|c|}{$T$} \\
\hline & NB & NM & NS & Z & PS & PM & $\mathrm{PB}$ \\
\hline NB & NB & NB & NM & NM & NS & NS & Z \\
\hline NM & NB & NM & NM & NS & NS & Z & PS \\
\hline NS & NM & NM & NS & NS & $\mathrm{Z}$ & PS & PS \\
\hline Z & NM & NS & NS & $\mathrm{Z}$ & PS & PS & PM \\
\hline PS & NS & NS & $\mathrm{Z}$ & PS & PS & PM & PM \\
\hline $\mathrm{PM}$ & NS & $\mathrm{Z}$ & PS & PS & PM & PM & $\mathrm{PB}$ \\
\hline $\mathrm{PB}$ & $\mathrm{Z}$ & PS & PS & $\mathrm{PM}$ & $\mathrm{PM}$ & $\mathrm{PB}$ & $\mathrm{PB}$ \\
\hline
\end{tabular}




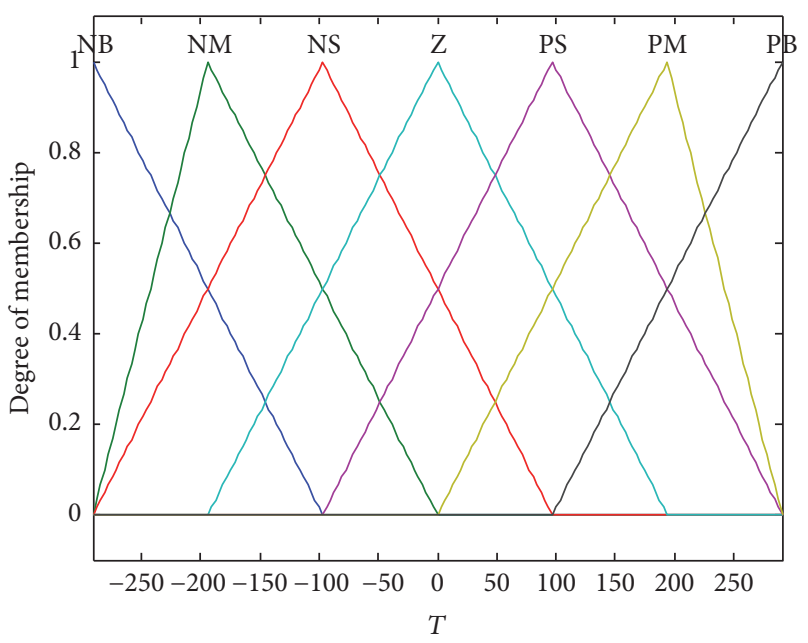

FIGURE 7: Curve of torque membership function.

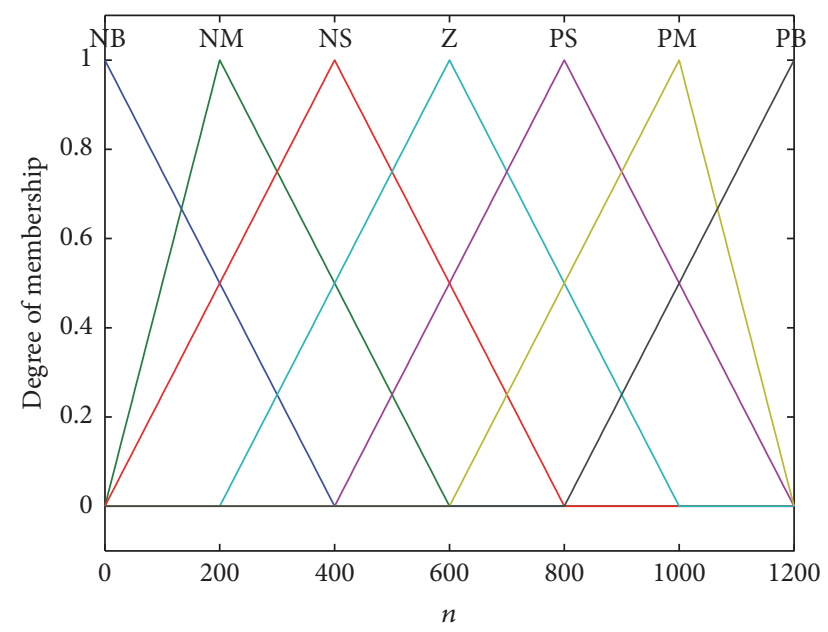

FIGURE 8: Speed membership function curve.

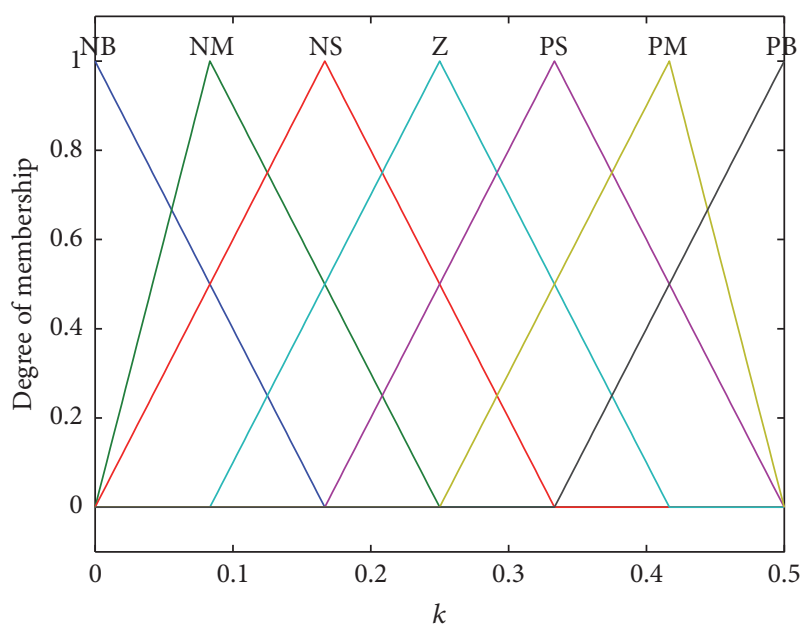

Figure 9: Outputs of the $k$ membership function curve.

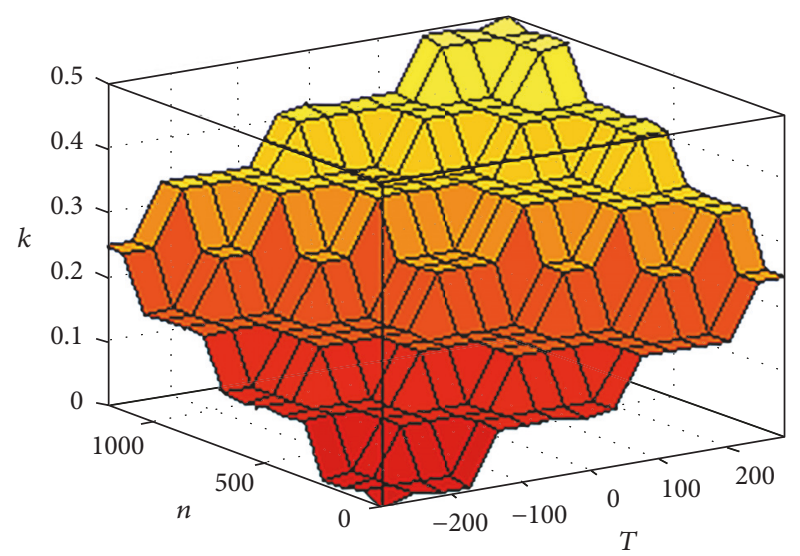

FIGURE 10: Fuzzy control strategy torque distribution factor.

TABLE 2: The basic parameters of the prototype car.

\begin{tabular}{lc}
\hline Parameter name & Value \\
\hline $\mathrm{M} / \mathrm{kg}$ & 2000 \\
Wheel base $/ \mathrm{m}$ & 2.5 \\
Wind ward area $/ \mathrm{m}^{2}$ & 2.60 \\
Wheel radius $/ \mathrm{m}$ & 0.27 \\
Centroid height $/ \mathrm{m}$ & 0.52 \\
Front track/m & 1.102 \\
Rear track $/ \mathrm{m}$ & 1.158 \\
\hline
\end{tabular}

After calculation, the torque distribution factor is obtained as shown in Figure 10.

Rule-based fuzzy control strategy is shown in Figure 11.

\section{Simulation Results Analysis}

In order to compare the effects of different control strategies on the torque distribution of the hub motor, the simulation research of the distributed drive system electric vehicle under the condition of NEDC is carried out. The working condition is shown in Figure 12. The experimental simulation parameters of vehicle are shown in Table 2.

The NEDC cycle is about $11.03 \mathrm{~km}$, with length of $1185 \mathrm{~s}$ and with an average speed of $33.65 \mathrm{~km} / \mathrm{h}$. By calculation, the maximum torque is $630.32 \mathrm{~N} \cdot \mathrm{m}$, and the maximum power is $48.57 \mathrm{~kW}$. The torque and power requirements of the simulation vehicle running under NEDC road conditions are shown in Figure 13.

5.1. The Torque Allocation Strategy of Four-Wheel Drive Based on Rule. The traditional distributed drive electric vehicle is based on the rule of average distribution and uses four-wheel drive at full time during the driving process. The motor operating point distribution of the NEDC road condition drive torque allocation strategy is shown in Figure 14.

For nonuniform conditions, according to the MAP efficiency of wheel motor we can see that the drive efficiency of the hub motor is low at the range of low speed and large torque, and the efficiency of the motor varies nonlinearly with 


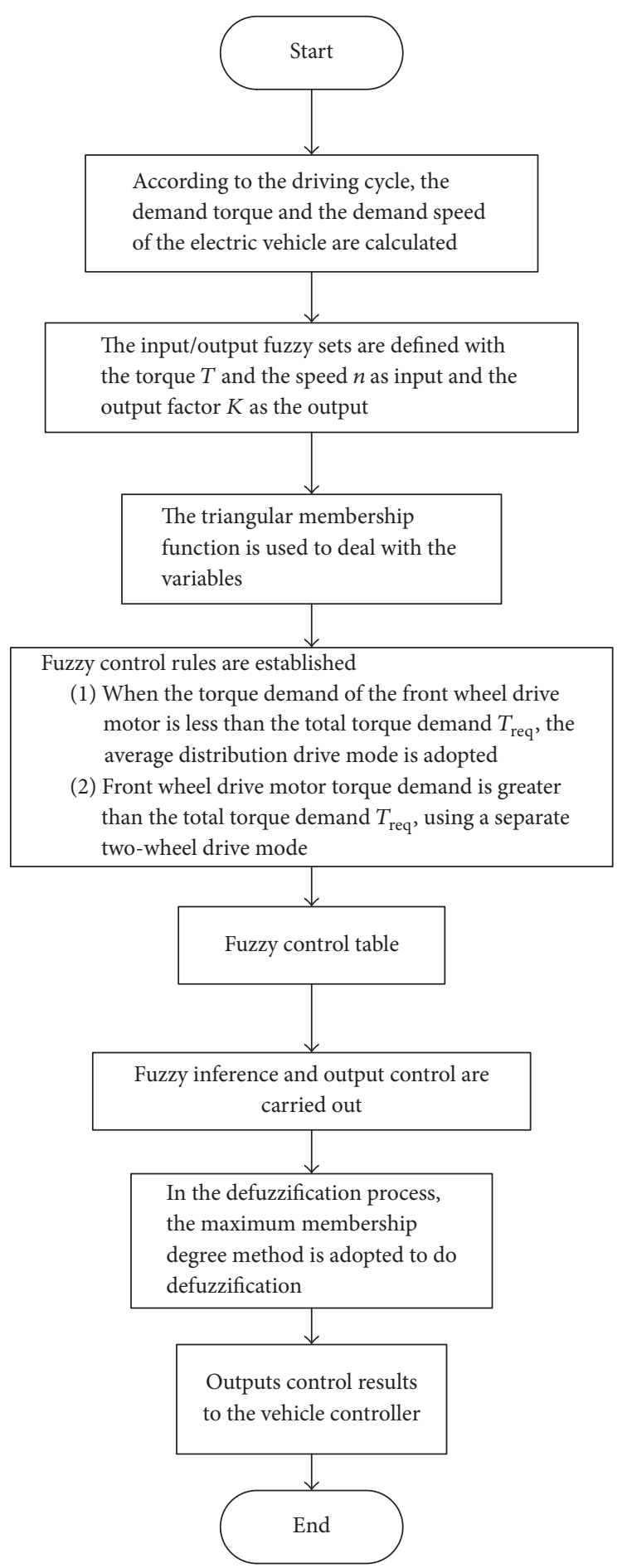

FIGURE 11: Fuzzy control algorithm to achieve torque distribution process.

the speed and torque. Due to the average torque allocation method based on rules without considering the factors of efficiency change, the motor would work in low efficiency area and impact the driving system comprehensive efficiency. The fixed proportion allocation method makes driving lack of follow-up and can not make the corresponding treatment

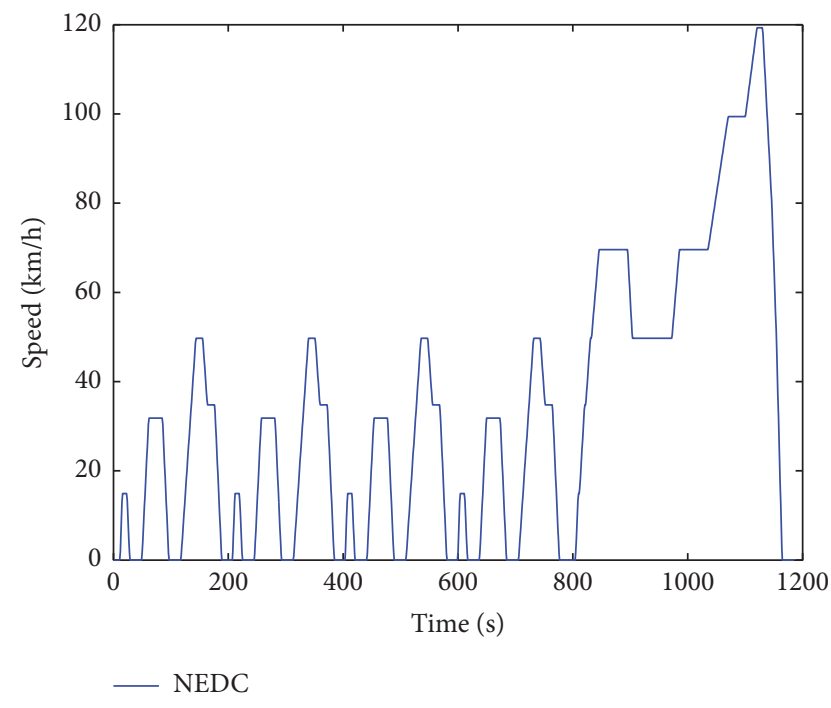

FIGURE 12: NEDC conditions.

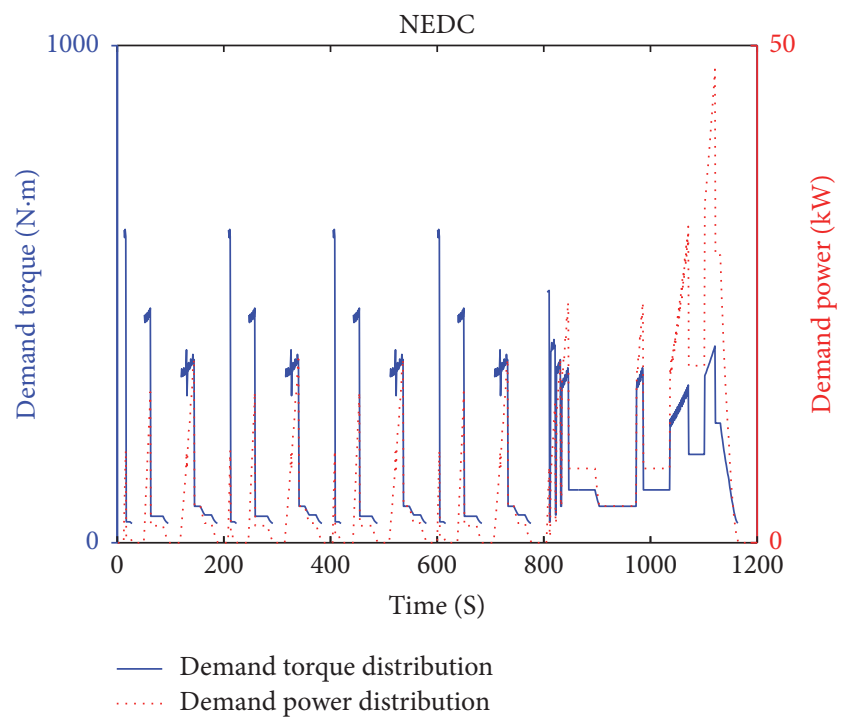

FIGURE 13: Demand power/torque diagram.

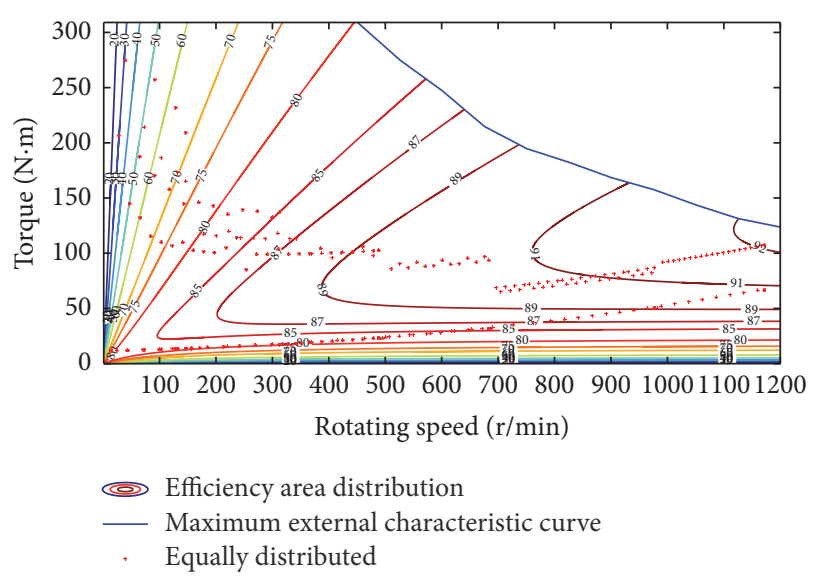

FIGURE 14: Distribution of motor working points under NEDC road condition. 


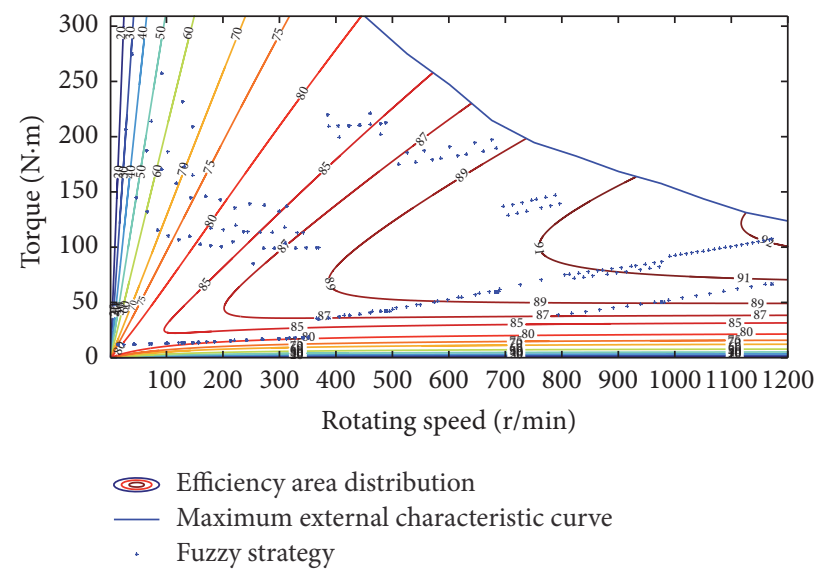

FIGURE 15: Distribution of motor working points under NEDC road condition.

according to the torque changes, which leads to the fact that the efficiency of motor decreases and the energy consumption increases. The application of the regular four-wheel drive torque distribution strategy is obtained by simulation: in a NEDC cycle, the electric drive system energy consumption is $8444 \mathrm{~kJ}$, and the energy consumption of electric drive system is $21.26 \mathrm{kWh}$ per 100 kilometers.

5.2. The Torque Distribution Strategy of Four-Wheel Drive Based on Fuzzy Rule. The torque distribution control strategy based on fuzzy rules is obtained according to the fuzzy inference. When the vehicle speed changes within a certain range, the distribution of four-wheel driving torque according to the actual vehicle driving demand for distributed drive electric vehicles until achieving switch control between four- and two-wheel drive, in order to improve the driving motor's work efficiency, reduces the energy consumption and increases the mileage. The drive torque distribution strategy of the motor operating point for the NEDC road condition is shown in Figure 15. The fuzzy control strategy is obtained through simulation, the energy consumption of the electric drive system is $8338 \mathrm{~kJ}$, and the energy consumption of the electric drive system is $20.99 \mathrm{kWh}$ per $100 \mathrm{~km}$. Compared with the conventional rule-based average allocation, the fuzzy control strategy reduces the energy consumption, and the motor work point is optimized.

5.3. The Torque Allocation Strategy of Four-Wheel Drive Based on Dynamic Programming. According to dynamic programming control strategies can obtain the global optimal torque distribution strategies, In the cycle, the torque is distributed between front and rear wheel according to the different torque demand of electric vehicles, in order to improve the motor work efficiency of the motor range, so that the overall energy consumption is minimum. The working point distribution of the motor for driving torque distribution strategy in NEDC road condition is shown in Figure 16, and the torque distribution factor is shown in Figure 17. The energy consumption is $8041 \mathrm{~kJ}$ of the electric drive system

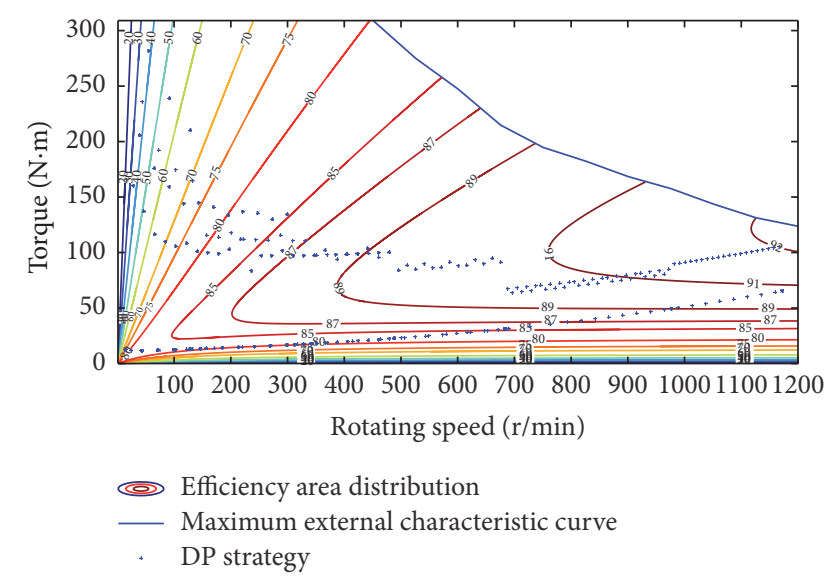

FIGURE 16: Distribution of motor working points under NEDC road condition.

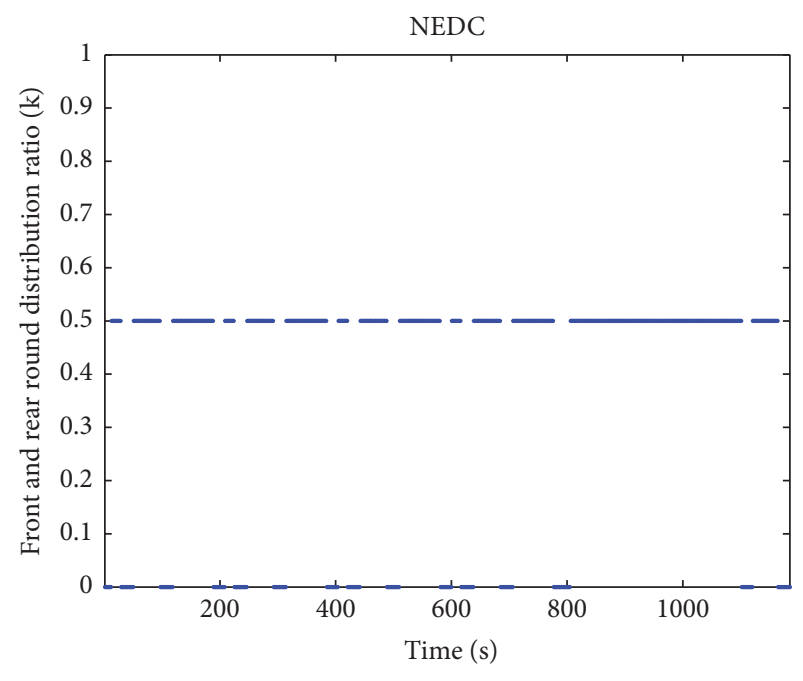

- DP distributed

FIgURE 17: Torque distribution factor diagram.

for dynamic programming control strategy, and the energy consumption is $20.25 \mathrm{kWh}$ of electric drive system per 100 kilometers.

As the dynamic programming control strategy is a global optimal control strategy, under the NEDC road conditions, the energy saving effect is better than that of the fuzzy control strategy based on experience and the control is more accurate. Thus, the motor operating point could be further optimized, so that the economy of the whole cycle is optimal.

Under the NEDC road condition, the contrastive analysis result of the energy consumption of the electric drive system for the simulation prototype is shown in Figure 18, and the motor efficiency comparison diagram is shown in Figure 19, and the comparison of the efficiency distribution of the motor is shown in Figure 20. As shown in Figure 18, when the dynamic programming optimization control strategy is used to achieve the four-round torque allocation, the energy consumption of the electric drive system is reduced by $3.5 \%$ 


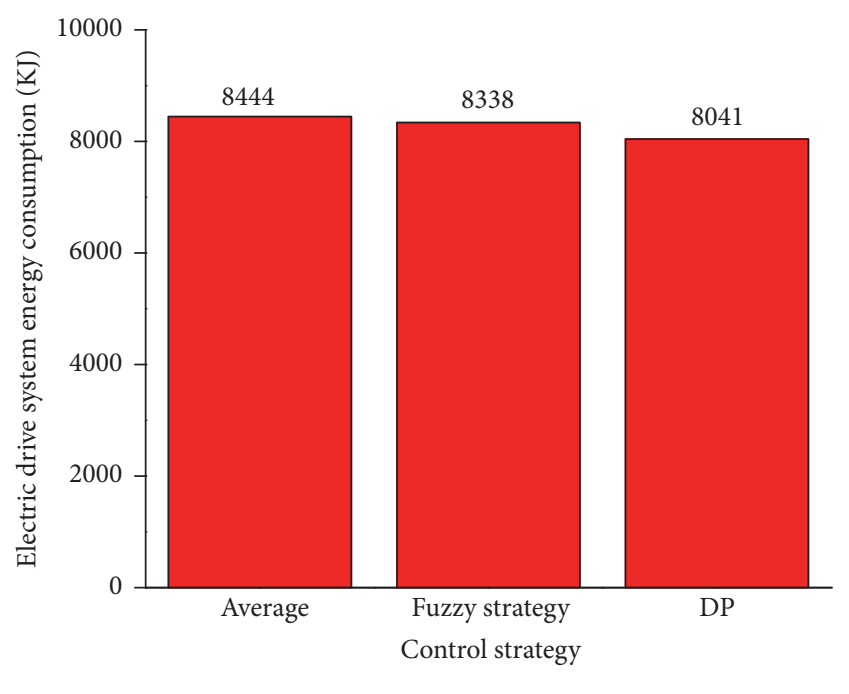

Electric drive system energy consumption

FIGURE 18: Energy consumption distribution diagram of electric drive system under NEDC road condition.

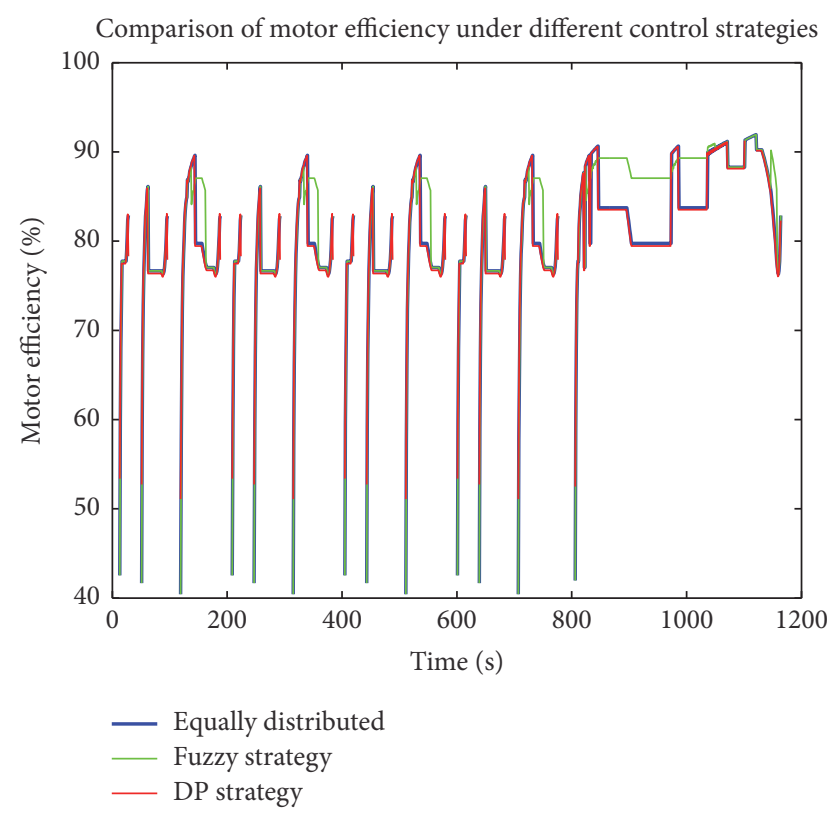

FIGURE 19: Motor efficiency comparison diagram of different control strategies under NEDC road condition.

compared to the fuzzy control strategy and is reduced by $4.77 \%$ compared to the average allocation strategy.

\subsection{Energy Consumption of One Hundred Kilometers' Electric} Drive System. Among the three different control strategies, the energy consumption of the $100 \mathrm{~km}$ electric drive system of the distributed drive system is shown in Figure 21. With the dynamic programming control strategy, the energy consumption of the $100 \mathrm{~km}$ electric drive system is reduced by $3.5 \%$ compared with the fuzzy control strategy and is reduced by $4.7 \%$ compared with the average allocation strategy.

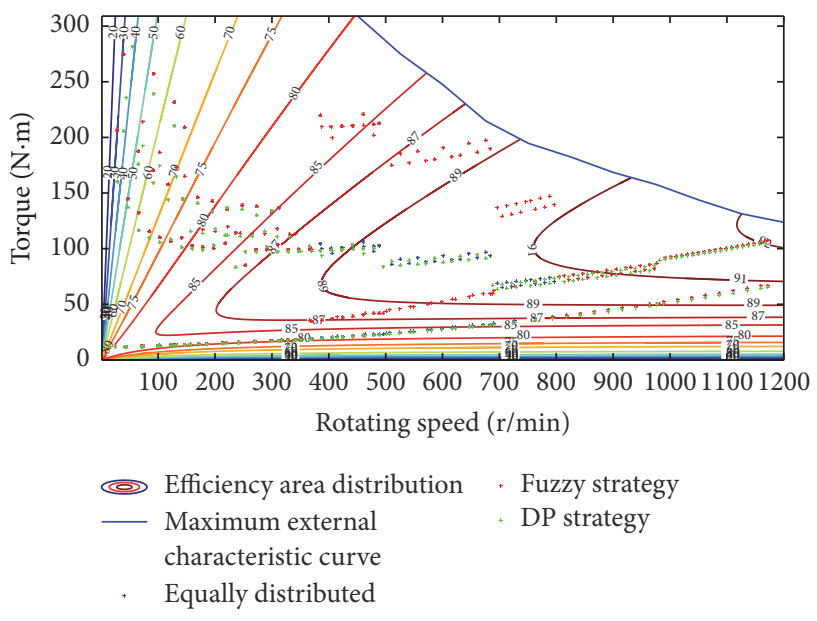

Figure 20: The comparison of the efficiency distribution of the motor.

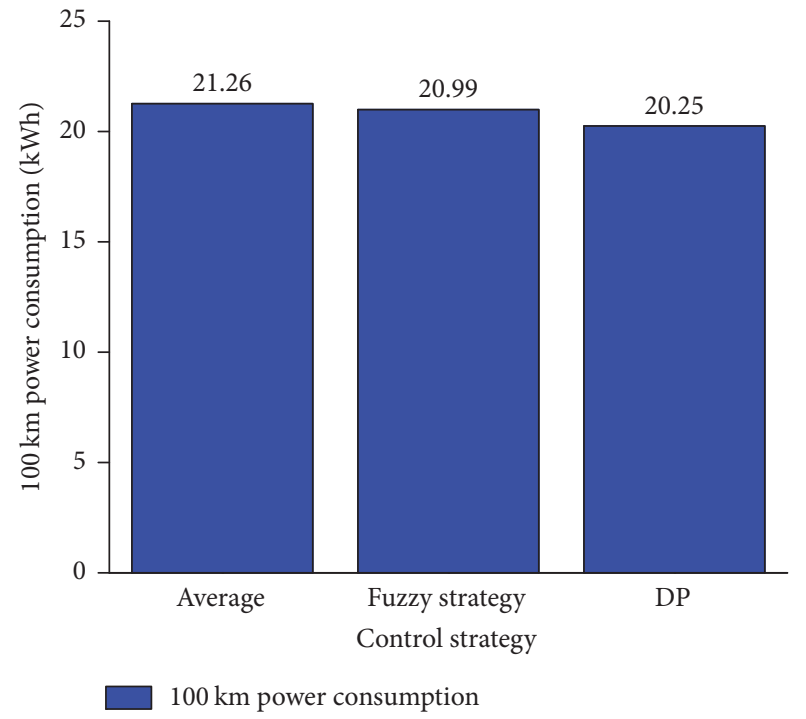

FIGURE 21: Energy consumption of one hundred kilometers' electric drive system.

\section{Summary}

Based on the hub motor distributed driving system model, the control effects of the distributed electric vehicle torque optimization allocation is contrasted among the dynamic programming control strategy, the fuzzy control strategy, and the rule-based control strategy under the NEDC road conditions. The details are shown below:

(1) Compared to the average allocation strategy of four wheel's torque distribution based on rules, the motor's working point can be optimized with the control strategy of dynamic programming under the NEDC road conditions. The energy consumption of the electric drive system is reduced by $403 \mathrm{~kJ}$, and the energy efficiency of the electric drive system is increased by $4.7 \%$. 
(2) Under the NEDC road condition, compared to the fuzzy control allocation strategy based on experience, the energy consumption of the electric drive system is reduced by $297 \mathrm{~kJ}$ with the dynamic programming control strategy, and the energy efficiency of the electric drive system is increased by $3.5 \%$.

(3) Using the optimal control method of dynamic programming under the NEDC road conditions, the energy consumption of electric drive system is $20.25 \mathrm{kWh}$ per 100 kilometers, which is reduced by $4.7 \%$ compared to that of the four-wheel average torque distribution strategy based rules and is reduced by $3.5 \%$ compared to that of the fuzzy control strategy.

In summary, under the fixed operation condition, the torque between the front and rear wheels can be reasonably allocated according to the driver control signal using the dynamic planning algorithm, and the overall energy efficiency of the electric drive system is optimal. Without considering the overall optimal fixed condition, compared to the four-wheel average distribution torque strategy, the fuzzy control strategy can still effectively improve the energy efficiency of the power system.

\section{Conflicts of Interest}

The authors declare that they have no conflicts of interest.

\section{Acknowledgments}

This work is supported by Key Laboratory of Advanced Manufacture Technology for Automobile Parts (Chongqing University of Technology), Ministry of Education Key Laboratory of Open Project Fund. This work is supported by 2015 application of technology research and development projects of Harbin City, scientific and technological innovation talents, and outstanding academic leaders A class, Project no. 2015RAXXJ009.

\section{References}

[1] L. Ma, J. Liu, and F. Yu, "Optimal control method for driving force of four-wheel independent electric vehicle," Automotive Engineering, vol. 32, no. 12, pp. 1057-1062, 2012.

[2] P. Shen, Z. Sun, Y. Zeng, X. Wang, and H. Dai, "Study on Power Ratio Between the Front Motor and Rear Motor of Distributed Drive Electric Vehicle Based on Energy Efficiency Optimization," in Proceedings of the SAE World Congress and Exhibition, 2016.

[3] Z. Guangcai, Y. Luo, and K. Li, "Longitudinal force optimal allocation method of four wheel independent electric vehicle," Journal of Tsinghua University (NATURAL SCIENCE EDITION), vol. 49, no. 5, pp. 111-115, 2009.

[4] K. Zhang, Study on Energy Efficiency Optimization Method of Pure Electric Vehicle, Tsinghua University, 2014, Zhang Kangkang.Study on Energy Efficiency Optimization Method of Pure Electric Vehicle.
[5] J. Yamakawa and K. Watanabe, "A method of optimal wheel torque determination for independent wheel drive vehicles," Journal of Terramechanics, vol. 43, no. 3, pp. 269-285, 2006.

[6] Z. Yu, L. Zhang, and L. Xiong, "Optimal torque sharing control of an improved 4WD Electric Vehicle," Journal of Tongji University: Natural Science Edition, vol. 33, no. 10, pp. 1355-1361, 2005.

[7] J. Zhu, R. Zheng, and Q. Shen, "Study on torque distribution strategy of wheel drive hybrid vehicle," Automotive Engineering, vol. 32, no. 11, pp. 967-972, 2010.

[8] C. Gu, L. Hao, and C. Xinbo, "Torque allocation of four wheel drive electric vehicle based on efficiency optimization," Journal of Tongji University (Natural Science Edition), vol. 43, no. 10, pp. 1550-1556, 2015.

[9] B. Wang, Y. Luo, J. Fan, and K. Li, "A study on driving force distribution of four-wheel-independent drive electric vehicle based on control allocation," Automotive Engineering, vol. 32, no. 2, pp. 128-132, 2010.

[10] D. Lu, M. Ouyang, J. Gu, and J. Li, “Torque distribution algorithm for a permanent brushless DC hub motor for fourwheel drive electric vehicles," Journal of Tsinghua University, vol. 52, no. 4, pp. 451-456, 2012.

[11] Z. Yu, Y. Feng, and L. Xiong, "Review on vehicle dynamics control of distributed drive electric vehicle," Journal of Mechanical Engineering, vol. 49, no. 8, pp. 105-114, 2013.

[12] R. Wang, Y. Chen, D. Feng, X. Huang, and J. Wang, "Development and performance characterization of an electric ground vehicle with independently actuated in-wheel motors," Journal of Power Sources, vol. 196, no. 8, pp. 3962-3971, 2011.

[13] H. He, J. Peng, R. Xiong, and H. Fan, "An acceleration slip regulation strategy for four-wheel drive electric vehicles based on sliding mode control," Energies, vol. 7, no. 6, pp. 3748-3763, 2014.

[14] J. Chen, J. Wu, X. Wu, and J. Du, "Study on energy management strategy based on DP for range extended electric bus in Chinese driving cycles," in Proceedings of the 2014 IEEE Transportation Electrification Conference and Expo, ITEC Asia-Pacific 2014, Beijing, China, September 2014.

[15] Y. Zou, S. Hou, E. Han, L. Liu, and R. Chen, "Dynamic programming-based energy management strategy optimization for hybrid electric commercial vehicle," Automotive Engineering, vol. 34, no. 8, pp. 663-668, 2012.

[16] Z. Y. Song, H. Hofmann, J. Q. Li, X. B. Han, and M. G. Ouyang, "Optimization for a hybrid energy storage system in electric vehicles using dynamic programing approach," Applied Energy, vol. 139, pp. 151-162, 2015.

[17] X. Dan, W. Guodong, and C. Binggang, "Study on torque optimal distribution strategy of independent drive electric vehicle," Journal of Xian Jiao Tong University, vol. 46, no. 3, pp. 42-47, 2012.

[18] G. Chen, X. Gu, and L. He, "An acceleration slip regulation strategy for four-wheel independent drive EV based on road identification," Sae World Congress \& Exhibition, vol. 83, no. 2, pp. 211-218, 2015.

[19] L. Dongqi, Z. Qingchang, and W. Yaonan, "Intelligent charging and discharging control of electric vehicle V2G based on synchronous inverter," Droceedings of the Chinese society of electrical engineering, vol. 37, no. 2, pp. 544-556, 2017.

[20] G. Yin, S. Wang, and X. Jin, "Optimal slip ratio based fuzzy control of acceleration slip regulation for four-wheel independent driving electric vehicles," Mathematical Problems in Engineering, vol. 2013, Article ID 410864, 7 pages, 2013. 
[21] H. Lin and C. Song, "Design of a fuzzy logic controller for ABS of Electric Vehicle based on AMESim and Simulink," in Proceedings of the 2011 International Conference on Transportation, Mechanical, and Electrical Engineering, TMEE 2011, pp. 779782, Changchun, China, December 2011. 


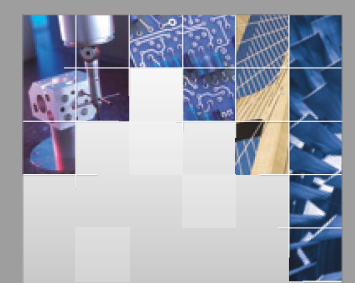

\section{Enfincering}
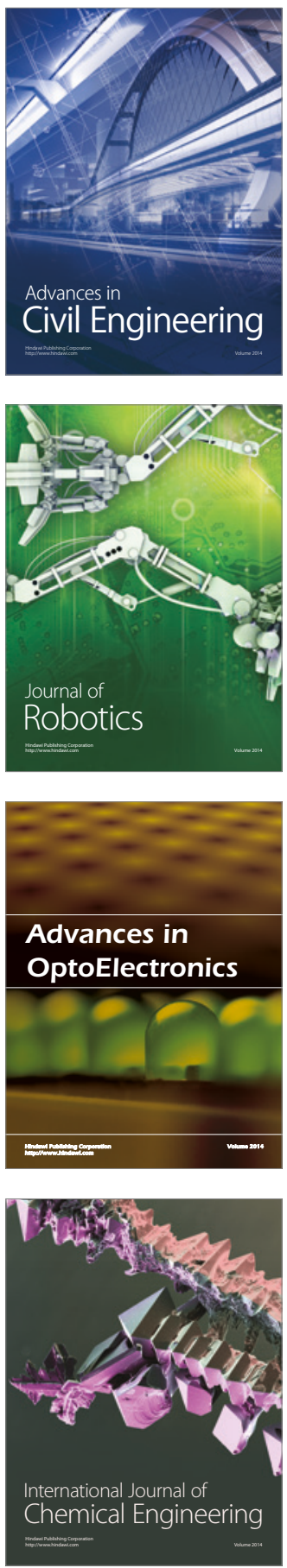

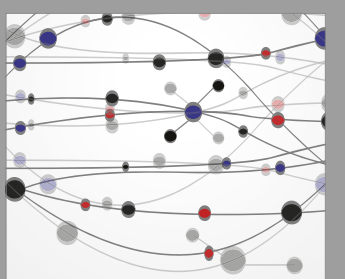

The Scientific World Journal

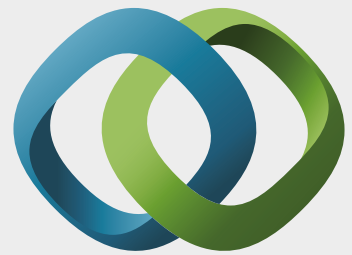

\section{Hindawi}

Submit your manuscripts at

https://www.hindawi.com
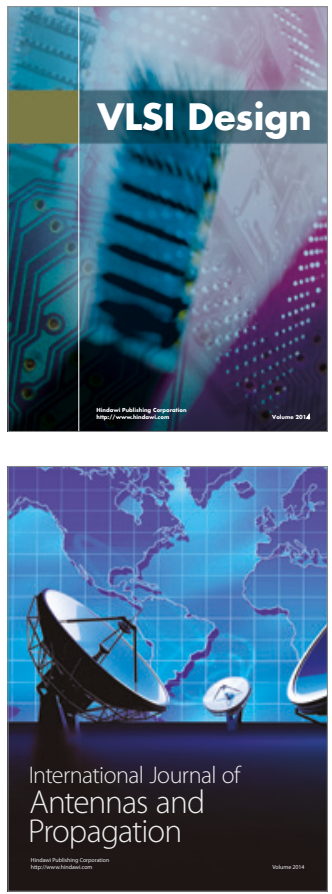

\section{Rotating}

Machinery
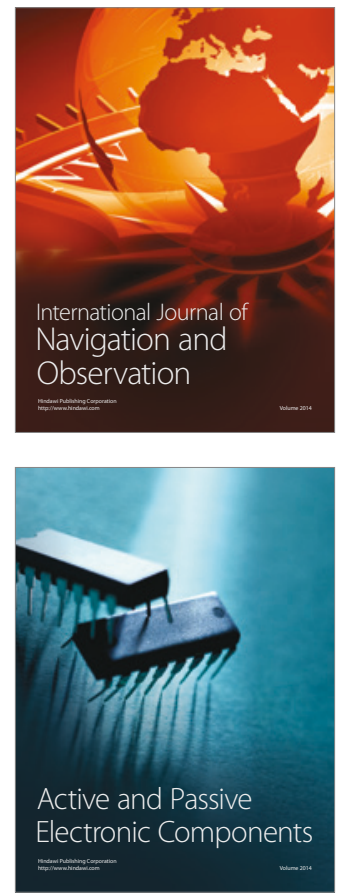
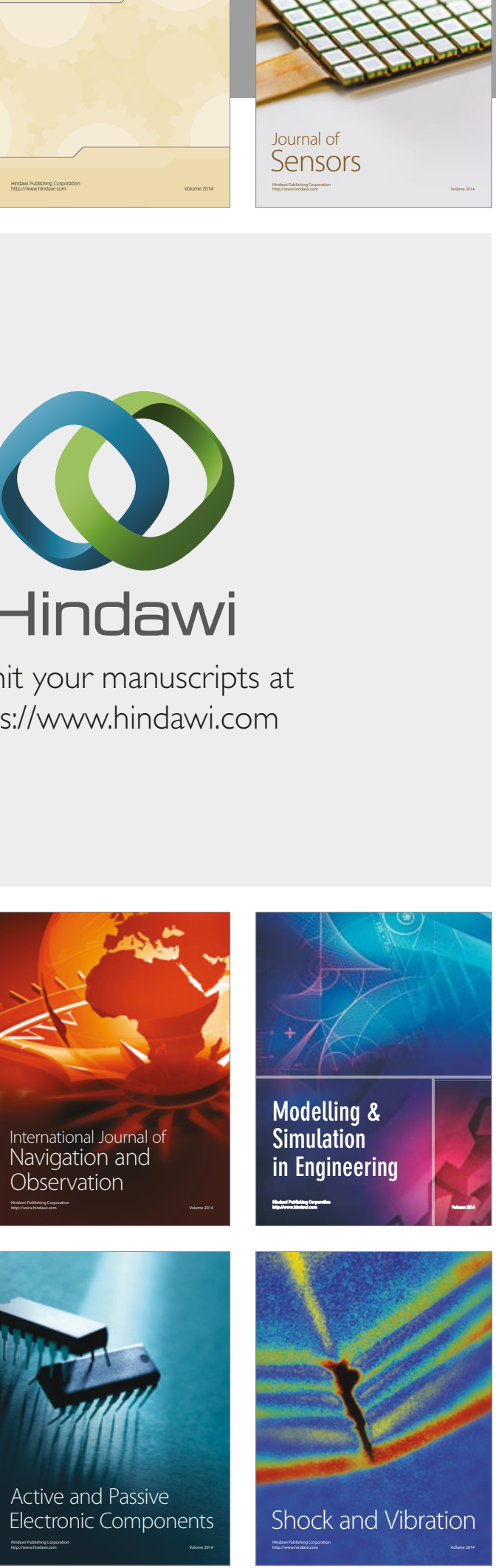
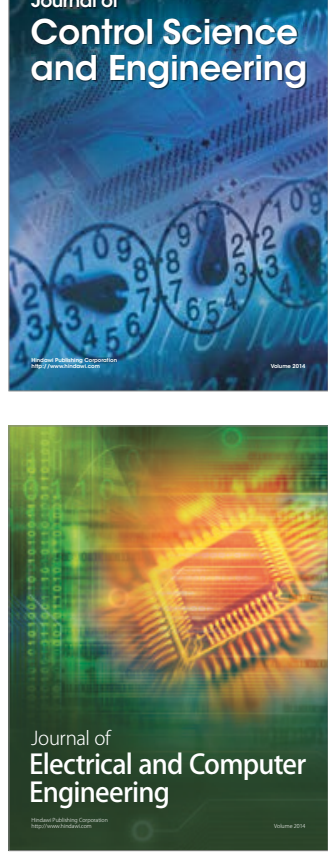

Distributed

Journal of

Control Science

and Engineering
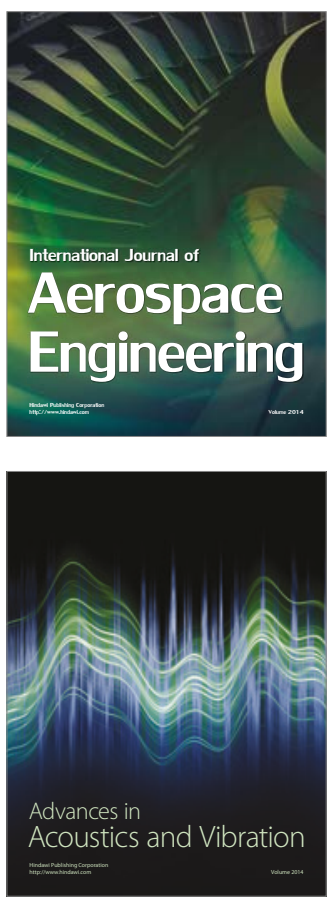

Sensor Networks 